\title{
Comments on "On the reported magnetic precursor of the 1989 Loma Prieta earthquake" by J.N. Thomas, J.J. Love, and M.J.S. Johnston
}

\author{
A.C. Fraser-Smith, P.R. McGill, and A. Bernardi \\ J.M.G. Glen, S.L. Klemperer, and D.K. McPhee \\ Correspondence: Simon Klemperer,sklemp@stanford.edu
}

A recent paper (Thomas et al., PEPI, 2009) sought to discredit observations by Fraser-Smith et al. (GRL, 1990) widely believed to represent a precursor to the 1989 Loma Prieta earthquake.

Our research group is confident that there are scientific errors, and errors of omission, in the Thomas et al. presentation. The attached Comments were submitted to PEPI to let the community understand that the reported magnetic precursor of the 1989 Loma Prieta earthquake is a subject of continuing discussion and uncertainty, and not - as Thomas et al. (2009) would have the community believe - a disproved hypothesis.

After more than six months had elapsed, the Editor of PEPI announced his decision to not publish our Comments. The Editor did not dispute that our Comments are scientifically sound. He simply decided that our Comments would not be of interest to readers of PEPI, even while explicitly stating that he did not mean that the Reply drafted by Thomas et al. had rebutted the arguments made in our Comments. We were told, "It is, perhaps, unfortunate that so much of the discussion addresses the possibility of instrument malfunction, which is not something of general interest" which begs the question of why PEPI decided to publish Thomas et al. (2009).

In order to affirm our belief that there remain scientific reasons to believe the reported magnetic precursor is likely a real precursor, we attach our Comments as submitted. In order to meet stringent word-length restrictions by PEPI, our comments were split into two separate Comments with separate authorship, even though all authors read and endorsed both. 


\title{
Comment on "On the reported magnetic precursor of the 1989 Loma Prieta earthquake" by J.N. Thomas, J.J. Love, and M.J.S. Johnston
}

\author{
A.C. Fraser-Smith ${ }^{\mathrm{a}}$, P.R. McGill ${ }^{\mathrm{b}}$, and A. Bernardi ${ }^{\mathrm{c}}$ \\ ${ }^{a}$ Departments of Electrical Engineering and Geophysics, Stanford University, Stanford, CA \\ 94305; acfs@stanford.edu \\ ${ }^{\mathrm{b}}$ Monterey Bay Aquarium Research Institute, Moss Landing, CA 95039. \\ ${ }^{c}$ ICoat Company, Santa Fe Springs, CA 90670.
}

Thomas et al. (2009) (hereafter TLJ09) attempt to cast doubt upon the report by FraserSmith et al. (1990) (hereafter FS90) of unusual large-amplitude ultra-low frequency (ULF; $\mathrm{f}<10 \mathrm{~Hz}$ ) magnetic fields preceding the $\mathrm{M} \sim 7$ Loma Prieta earthquake. TLJ09 suggest there are instrumental problems with FS90's data that we, the designers, builders and long-term operators of the equipment, are presumed to have been unable to identify. We refute these claims and demonstrate that TLJ09's conclusion, that the large-amplitude magnetic fields were an artifact of faulty amplifiers, is false.

The equipment recording FS90's ULF measurements was the product of two decades of research on ULF fluctuations of Earth's magnetic field and was installed at Corralitos, California, roughly two years prior to the time of the Loma Prieta earthquake whose epicenter was located only $7 \mathrm{~km}$ distant.

TLJ09's argument that large-amplitude magnetic fields reported in FS90 were merely the product of faulty amplifiers depends on a comparison with two remote measurement sites, Kakioka, Japan, and Fresno, California, 8,288 km and $185 \mathrm{~km}$ (great-circle distances) from Corralitos. But Kakioka is too distant for it to record a signal local to California and the magnetic-field activity generated on its field lines in the magnetosphere (source region for ULF fluctuations) differs fundamentally from that generated on the Corralitos field lines. Fresno is also a poor comparison: it only recorded below the $0.01-10 \mathrm{~Hz}$ range of the Corralitos system, without any overlap. TLJ09 filtered the Fresno data from $0.0010-0.0083 \mathrm{~Hz}$ describing this as "slightly below the lowest frequency COR index MA\#3", and merely a "subtle" and "technical difference". Nothing is further from the truth: the TLJ09 range covers part of the Pc 4 pulsation band, the entire Pc 5 band, and part of the Pc 6 band (Jacobs, 1970). Each different band covers different forms of activity, so TLJ09's composite Fresno index cannot be representative of activity measured at Corralitos.

Most unfortunately, TLJ09 filtered the Corralitos, Kakioka and Fresno data to remove their diurnal variations. Since these diurnal variations are a fundamental feature of naturally occurring geomagnetic pulsations, this filtering prevented TLJ09 from detecting the lack of diurnal variation in the large-amplitude ULF signals immediately preceding the earthquake at Corralitos, a clear indication that they were not amplified normally occurring activity.

Our ULF magnetic-field measurement systems always include an independently generated known magnetic signal (CAL) injected into their sensors to provide a continuous check on performance. The Corralitos system used a single-turn coil, inserted 
between the two solenoids comprising its sensor, to inject a known magnetic-field variation into the sensor (Bernardi et al., 1989). The current through the single-turn coil was generated by a simple oscillatory circuit independent of any other electronics in the measurement system. Should this circuit fail, the CAL signal would immediately disappear and its failure would be obvious. The signal injected into the sensor by this independent CAL circuit was amplified by the same low-noise, high-gain amplifiers used to amplify the naturally occurring magnetic signals, then subjected to all the subsequent processing used to produce the final MA indices, to provide an equivalent MA index displayed as CAL in FS90.

The CAL frequency was set at $12.5 \mathrm{~Hz}$, just above the nominal $0.01-10 \mathrm{~Hz}$ range of operation of the magnetometer but well within the normal frequency range of our amplifiers and other system electronics. The CAL input amplitude was set substantially greater than the normal low background noise at $12.5 \mathrm{~Hz}$ (corresponding to the first minimum in the Schumann resonance range), so that the CAL measurement remains essentially constant during normal operation of the measurement system. (Although naturally occurring magnetic activity at $12.5 \mathrm{~Hz}$ is conspicuously weak it can produce small changes in the measured CAL index.) This independent CAL signal subjects the Corralitos amplifiers to a continual, sensitive check. A change in amplifier gain would immediately show up as a variation in the amplitude of the CAL measurement. This CAL signal was processed and appended as a status measurement to each set of MA indices produced by the Corralitos system.

TLJ09's Figure 1 shows the CAL signal at Corralitos remained steady for the entire 21month period they discuss, except during power outages. A small jump in the CAL signal immediately followed replacement of the preamplifier on $7 / 10 / 1990$, as described in our Corralitos system log (TLJ09 Table 1), but the data remain calibrated and there is no indication of any other amplifier gain change during the period. In particular, there are no changes in the CAL signal in the months preceding the Loma Prieta earthquake. These thousands of measurements of amplifier gain, with no indication of any changes, are impossible to reconcile with TLJ09's speculation that the anomalous signals preceding the earthquake were the product of a faulty amplifier.

TLJ09 repeatedly quote from our system log that an amplifier was replaced on 7/10/1990. They speculate that an earlier failure of this amplifier produced the anomalous signals prior to the earthquake. But the CAL signal at no time indicated any amplifier failure, even during the obvious and clearly flagged interval of apparent system failure during July 1990. The CAL signal displays only small changes, which are inconsistent with the very large amplifier-gain changes needed to explain the large observed signals. Instead, it was obvious to the magnetometer operators that the large signals were being produced by noise within the magnetometer circuitry. Replacement of the amplifier at this time was a routine maintenance step; more important is the entry omitted from TLJ09's quotes from our log: "Inspected and cleaned all connectors to the preamp and ohmed out cables - all are okay." It was only after these latter actions that the system measurements returned to normal. In its operators' view, the system was clearly suffering from electrolytically generated noise from corrosion in a connector leading to or associated 
with the preamp. Under normal circumstances, when the Corralitos facilities were not severely damaged and under reconstruction, routine maintenance would have prevented such occurrences. TLJ09's speculations about amplifier failure cannot be reconciled with the facts.

Bernardi, A., A.C. Fraser-Smith, and O.G. Villard, Jr., 1989. Measurement of BART magnetic fields with an automatic geomagnetic pulsation index generator, IEEE Trans. Electromagn. Compat., 31, 413-417.

Fraser-Smith, A.C., A. Bernardi, P.R. McGill, M.E. Ladd, R.A. Helliwell, and O.G. Villard, Jr., 1990. "Low-frequency magnetic field measurements near the epicenter of the Ms 7.1 Loma Prieta earthquake," Geophys. Res. Letters, 17, 1465-1468.

Jacobs, J.A., 1970. Geomagnetic Micropulsations, 179 pp., Springer-Verlag, N.Y.

Thomas, J.N., J.J. Love, and M.J.S. Johnston, 2009. "On the reported magnetic precursor of the 1989 Loma Prieta earthquake,” Phys. Earth Planet. Int., 173, 207-215. 


\title{
Comment on "On the reported magnetic precursor of the 1989 Loma Prieta Earthquake" by J. N. Thomas, J. J. Love, and M. J. S. Johnston
}

\author{
J.M.G. Glen ${ }^{\mathrm{a}}$, S.L. Klemperer ${ }^{\mathrm{b}}$, D.K. McPhee \\ ${ }^{a}$ U.S. Geological Survey, 345 Middlefield Road, Menlo Park, CA 94025, USA. \\ b Department of Geophysics, Stanford University, CA 94305, USA; sklemp@stanford.edu; to \\ whom correspondence may be addressed
}

Thomas et al. (2009) (hereafter TLJ09) attempt to model, as due to instrumental problems, the anomalous electromagnetic observations prior to the Loma Prieta earthquake that were first reported as likely earthquake precursors (Fraser-Smith et al., 1990). In contrast, we believe the most straightforward interpretation of the limited available data (Fraser-Smith et al., 1990), including the single most compelling feature 100 times above background levels, appearing just three hours before the earthquake, but barely mentioned by TLJ09 - is as a true earthquake precursor.

TLJ09 conclude that "sensor-system malfunction" - a change in signal amplification due to amplifier problems - were the cause of the anomalous signals (wideband anomalies, W1 in TLJ09 figure 1) recorded prior to the Loma Prieta earthquake. That this is precluded by the recorded calibration signal is the subject of a separate comment (FraserSmith et al., submitted). TLJ09 then focus on wideband amplifications in July 1990 (W3, TLJ09 figure 1), during a period of known instrument malfunction (TLJ09 Table 1). These wideband energy increases W3 are likely due to connector problems - similar amplitude fluctuations are present across all frequencies, and the anomalous signals disappeared following cleaning of connectors as documented in the station logbook (TLJ09 Table 1). Nonetheless, TLJ09 suggest that the existence of any instrumental problems discredits all anomalous signals from the same system.

However, we can categorically state that equivalent problems could not have produced the wideband signal W1 prior to Loma Prieta earthquake. W1 had three clear characteristics (Fraser-Smith et al., 1990) that are distinct from W3, that are not addressed by TLJ09, that no-one has successfully modeled with instrument malfunction, and that are all likely hallmarks of true precursors:

(1) wideband signals W1 prior to the Loma Prieta earthquake are more strongly amplified at low frequencies than at high frequencies, in exactly the manner as would be required of a source internal to the earth at depths of earthquake nucleation (several skin depths for the highest frequencies);

(2) wideband signals W1 prior to the Loma Prieta earthquake show an increasing multi-day trend, but the rapid geomagnetic pulsations become proportionally smaller, in exactly the manner required if a local (earthquake-precursor) source was beginning to drown out the global ionospheric signals ;

(3) wideband signals W1 prior to the Loma Prieta earthquake dramatically increase to a factor of x100 over the background in a period of three hours immediately prior to the earthquake, with a character nowhere else seen on the multi-year recordings, providing the singular observation expected from the singular large close seismic event during our recording period. 
No retrospective analysis can ever conclusively show whether the anomalous signals recorded prior to the Loma Prieta earthquake were due to failure of the recording system in a way that no-one has yet been able to model, or whether they were true earthquake precursors as modeled in several studies (Merzer \& Klemperer, 1997; Simpson \& Taflove, 2005, and refs. therein). The attempt by TLJ09 to explain away the Loma Prieta signals as amplifier problems follows their earlier attempt to explain away the Loma Prieta signals as due to timing errors (Thomas et al. 2007), an attempt that TLJ09 have ignored since its comprehensive rebuttal by Culp et al. (2007). Because no attempts to model the anomalous data as due to instrumental malfunction (Campbell, 2009; Thomas et al., 2007, 2009) pass simple tests (Culp et al., 2007; Fraser-Smith et al., 2011, submitted), we conclude that the Corralitos data-set most probably captures a true earthquake precursor.

A negative assessment of the Loma Prieta observations requires proof to demonstrate the signal is an artifact. Simply suggesting that the signal might arise from faulty equipment is not sufficient to dismiss the record. Instead, the criteria on which to judge the precursor signal should be based on the positive identification of known characteristics of a faulty component.

Limitations in the Fraser-Smith et al. (1990) data imposed by then-available 1980s technology cannot be overcome by forensic analysis. Reinforcement of our conclusion that the anomalous signals recorded at Corralitos were likely earthquake precursors can only be achieved by an attempt to record analogous signals from other earthquakes through a renewed program of observation at multiple sites as is now being pursued by NSF, USGS, NASA and private organizations.

Campbell, W. H., 2009. Natural magnetic disturbance fields, not precursors, preceding the Loma Prieta earthquake. J. Geophys. Res., 114, A05307, doi:10.1029/2008JA013932.

Culp, D., Klemperer, S., Glen, J., McPhee, D., 2007. Re-affirming the Magnetic Precursor to the 1989 Loma Prieta, CA, Earthquake Using Magnetic Field Data Collected in the US in 1989 and 1990. EOS Trans. $A G U$, 87, S41D-03 http://www.agu.org/meetings/fm07/fm07-sessions/fm07 S41D.html and https://geo.stanford.edu/researchgroups/crustal/sites/default/files/CulpKlemperer.LomaPrieta.AGUtalk $.20070 . \mathrm{pdf}$

Fraser-Smith, A.C., Bernardi, A., McGill, P.R., Ladd, M.E., Helliwell, R.A., Villard, O.G., Jr., 1990. Lowfrequency magnetic field measurements near the epicenter of the Ms 7.1 Loma Prieta earthquake. Geophys. Res. Letts, 17, 1465-1468.

Fraser-Smith, A. C., McGill, P. R., Bernardi, A., 2011. Comment on "Natural magnetic disturbance fields, not precursors, preceding the Loma Prieta earthquake” by Wallace H. Campbell. J. Geophys. Res., 116, A08228, doi:10.1029/2010JA016379.

Fraser-Smith, A. C., McGill, P. R., Bernardi, A., submitted. Comment on "On the reported magnetic precursor of the 1989 Loma Prieta earthquake” by J. N. Thomas, J. J. Love, and M. J. S. Johnston. Phys. Earth Planet. Int.

Merzer, M., Klemperer, S.L. 1997. Modeling low-frequency magnetic-field precursors to the Loma Prieta earthquake with a precursory increase in fault-zone conductivity. PAGEOPH, 150, 217-248.

Simpson, J.J., Taflove, A., 2005. Electrokinetic effect of the Loma Prieta earthquake calculated by an entire-Earth FDTD solution of Maxwell's equations. Geophys. Res. Lett. 32, L09302, doi:10.1029/2005GL022601.

Thomas, J. N., Love, J. J., Johnston M. J. S., 2009. On the reported magnetic precursor of the 1989 Loma Prieta earthquake. Phys. Earth Planet. Int., 173, 207-215.

Thomas, J. N., Love, J. J., Johnston M. J. S., 2007. The 1989 Ms 7.1 Loma Prieta, California, magnetic earthquake precursor revisited. EOS Trans. $A G U, \quad$ 87, http://www.agu.org/meetings/fm07/fm07-sessions/fm07 S41D.html 